\title{
Method for Site Access Control
}

\author{
Emil Lutcerovich Khaziev', Lenar Ajratovich Galiullin² \\ ${ }^{1}$ PhD, Associate Professor, Kazan Federal University, Russia. \\ ID Scopus: 57211314209, ORCID: 0000-0002-8331-8852 \\ ${ }^{2} \mathrm{PhD}$, Associate Professor, Kazan Federal University, Russia. \\ ID Scopus: 39361435200, ORCID: 0000-0001-8640-1734,
}

\begin{abstract}
An automated system for checking the availability of sites was implemented. To develop the service, the Silex micro PHP framework was used, the service architecture was also described, and a user guide for administrators was shown. All requirements were implemented according to the terms of reference. Today, the development of business sites, which is becoming the desired field of activity, is becoming increasingly important, since the company's website on the Internet is a fairly inexpensive and massive way of advertising and allows potential and current customers to easily receive information about the company's products and services, its business interests, which can help you find new customers and business partners, and thereby help you increase your sales and profitability. As the number of projects increases, the number of hosting and servers necessary for the stable operation of all projects increases, over time, resource control takes more and more time for the executors, and therefore, workflow automation is also necessary in the field of web studios. One of the necessary points for automation is working with servers and hosters.
\end{abstract}

Keywords: site; web; control; method; host.

\section{INTRODUCTION}

Today, any modern company has its own website. In the modern world, this is one of the elements of prestige, because it is on the Internet that potential customers are primarily looking for information about the company [1]. And if she doesn't even have a pricing page, this may seem suspicious.

The relevance of developing your own representative offices on the Internet is that if you want to communicate information about yourself to a huge number of people, without reference to the region or even the country, while spending a minimum of money and in a short time - more efficient than using your own website in the modern world automation and high technology to do this will not work [2]. The web resource allows you to provide detailed and complete information about the company, about its manufactured and sold goods, about the services provided. The site also makes it possible to purchase or fill out an application online, it can report on company news, new products, changes in the cost or mode of operation, contain both written and video reviews of grateful customers.
The importance of creating sites is explained by the following factors:

-speed of presentation of information to a wide group of people;

-the ability to organize customer feedback;

-improving the image of the company and increasing its popularity;

-marketing research organization;

-advertising and attracting customers and customers;

-prompt communication with branches and representative offices in various parts of the country and abroad.

It should be noted that you should not limit yourself to just creating a site. It will need to be developed and maintained, "promoted" and replenished in a timely manner, and this is not an easy task.

\section{METHODS}

A workflow is a process that involves many small, definable tasks. All processes take many forms in the workplace and can take anywhere from one day to completion.

In a small company, any workflow can take a long time to complete manually, but it is not an impossible task. [3] And the larger the business becomes, the more time this or that task takes [4]. It was at that moment that automation turned into a necessity [5]. Automation of all processes increases the speed of information processing and reduces labor costs.

Today, the development of websites for companies, which is becoming a popular line of business, is of particular relevance, as the company's website on the Internet is a fairly inexpensive and effective way of delivering information to existing and potential customers [6]. Having your own page or a full-fledged website on the World Wide Web also inspires confidence and serves to build the image of the company.

To create their own website and promote services, companies turn to specialized web studios to create and promote websites [7]. After creating a website, many customers need to promote services on the Internet, but some use the website only as a business card so that potential customers can study company information or see a list of services provided [8]. Often, these companies do not 
understand what is necessary for the stable operation of sites, and transfer all tasks to a web studio, which, in turn, provides services for the promotion and technical support of sites [9]. One type of service is the provision of hosting services for customers.

Hosting is the placement of Internet projects on physical and virtual servers connected to the Internet to continuously ensure the presence of sites on the network [10]. Speaking in a more understandable and simple language, this is a service that will provide your Internet resources with an Internet presence for the period for which you ordered and paid for this service.

When choosing a hosting site, you must be guided by the characteristics of the server, fault tolerance indicators, the physical location of the data center, the availability of technical support and advice.

The developed website should be accessible around the clock and work even on weekends and holidays. Therefore, it must be periodically checked both for accessibility and for proper operation.

As the number of projects supported by developers increases, the number of hosting and servers necessary for the stable operation of all projects increases, over time, resource control takes more and more time for executors, and therefore workflow automation is also necessary. One of the necessary points for automation is working with servers and hosters.

\section{RESULTS AND DISCUSSION}

One of the criteria for a website to work effectively is the constant availability of its materials to visitors. It would seem that it is not so difficult to periodically monitor sites, but when the number of sites increases, a manual check of accessibility takes too much time. One way to solve the problem of wasting time and labor costs is to create a service with the ability to automatically monitor web sites.

The service is intended for checking the availability of sites, monitoring hosting, preparing accounts and contracts for clients, as well as sending notifications to a technical specialist who can solve the problem if necessary. The program is designed to reduce the risk of information loss, as well as monitoring the operation of all sites and hosting.

It is assumed that any full-time specialist can work with the program, for example, an accountant, document manager or system administrator, respectively, the interface of the implemented program should be easy to use by specialists of any level of training.

The service should be a simple and convenient web service to control the availability of all projects that are serviced by the company. For each user, you must provide your account to $\log$ in. After authorization, the user has the opportunity to add information to directories, namely, adding text templates, editing tariff plans, adding server and hosting addresses of the company, types of settlements, adding and editing information about existing projects.
Information should be displayed on projects:

-name

-type of calculation;

-tariff

-price

-name and access to the server where the site is located;

-customer contact phone number;

-contact email of the client;

-domain end date

-beginning and end of the service period;

-status;

-code with information about the availability of the site;

-the ability to edit information;

-the ability to print the contract, according to a pre-prepared template.

-the ability to filter by activity;

-the ability to filter by type of calculation, tariff, servers, hosters.

In the accounts you need:

-order name;

-beginning and end of the service period;

-date of payment for customer services;

-service tariff;

-type of calculation;

-amount

-account creation date;

-the ability to edit the account if necessary;

-the ability to add a comment;

-the ability to filter by active and inactive orders.

Based on the foregoing, we can distinguish functional and non-functional requirements for the development of AIS.

Functional requirements:

1) The system must identify users by login and password.

2) The system should check the availability of sites added to the service.

3) The system should display information about the domain validity period.

4) It should be possible to prepare an agreement on the customer details.

5) It should be possible to prepare an invoice for customer details. 
Non-functional requirements:

1) It should be possible to edit added projects.

2) All work with the service should be carried out through a convenient web interface, which should implement the following features - adding information to directories (tariffs, servers, hosters, types of interaction).

3) It should be possible to generate reports on accounts.

\section{SUMMARY}

The BPMN specification describes conventions for displaying business processes in the form of business process diagrams. BPMN is addressed to both technical experts and business users. To do this, the language uses a basic set of intuitive elements that allow you to define complex semantic constructions.

The starting event is the beginning of the week or, in other words, the client manager once a week searches for a new client. For this, the customer database is viewed. An offer is sent to selected customers. If the sent quotation suits the client, the client sends a positive response in the form of an email. The following is the conclusion of the contract, the client is charged for the services provided. After the customer pays the bill, the final event is that the project is added to the accessibility check service.

In order to increase the efficiency of the technical department, reducing the labor and financial costs of the company, a service was developed to check the availability of web sites.

To develop the service, the Silex micro PHP framework was used, using components from Symfony.

Silex has an intuitive API that makes the development process very enjoyable and allows you to add its functionality to the structure in just a few steps; however, Silex can be expanded to a full-stack MVC framework.

Model-View-Controller (MVC, "Model-View-Controller", "Model-View-Controller") - a scheme for dividing application data, user interface and control logic into three separate components: model, view and controller - so the modification each component can be performed independently.

\section{CONCLUSIONS}

An automated system for checking the availability of sites was implemented. To develop the service, the Silex micro PHP framework was used, the service architecture was also described, and a user guide for administrators was shown. All requirements were implemented according to the terms of reference.

Today, the development of business sites, which is becoming the desired field of activity, is becoming increasingly important, since the company's website on the Internet is a fairly inexpensive and massive way of advertising and allows potential and current customers to easily receive information about the company's products and services, its business interests, which can help you find new customers and business partners, and thereby help you increase your sales and profitability.

As the number of projects increases, the number of hosting and servers necessary for the stable operation of all projects increases, over time, resource control takes more and more time for the executors, and therefore, workflow automation is also necessary in the field of web studios. One of the necessary points for automation is working with servers and hosters.

The aim of the work was to increase the efficiency of the technical department of the company by creating and implementing an automated system for checking the availability of sites. To achieve this goal, such actions as domain analysis were performed, the organization was verified, business process models were compiled using IDE0, BPMN methodology, a control system design using UML technologies, a functional model was developed, system algorithms were developed to implement the system site availability management.

To implement the service, the Silex micro PHP framework was used.

\section{ACKNOWLEDGEMENTS}

The work is performed according to the Russian Government Program of Competitive Growth of Kazan Federal University.

\section{REFERENCES}

[1] Khuzyatov SS, Galiullin LA. Methodology for developing a web configurator for technology cabinets. Indonesian Journal of Electrical Engineering and Computer Science. 2020;19(1):42-46.

[2] Valiev RA, Galiullin LA. Internal Combustion Engines Fault Diagnostics. Lecture Notes in Electrical Engineering, Volume 641 LNEE, 2020:305-314.

[3] Valiev RA, Galiullin LA. Developing a Technical Diagnostic Systems for Internal Combustion Engines. Lecture Notes in Electrical Engineering, 641 LNEE. 2020:797-805.

[4] Valiev RA, Galiullin LA. Development of HardwareAlgorithmic System for ICE Diagnostics. Lecture Notes in Mechanical Engineering? 2020:457-467.

[5] Khuzyatov S, Valiev R. The Method of Automated Configuration Objects of the WinCC Project for the Oil and Gas Industry. Lecture Notes in Electrical Engineering. 2020;641:986-993,.

[6] Khuzyatov ShSh, Valiev RA. Organization of data exchange through the modbus network between the SIMATIC S7 PLC and field devices. 2017 International Conference on Industrial Engineering, Applications and 
International Journal of Engineering Research and Technology. ISSN 0974-3154, Volume 13, Number 11 (2020), pp. 3551-3554

(C) International Research Publication House. https://dx.doi.org/10.37624/IJERT/13.11.2020.3551-3554

Manufacturing, ICIEAM 2017 - Proceedings, article. 2017;8076369.

[7] Valiev RA, Khuzyatov ShSh. Pattern-design software of automated control systems. 2016 2nd International Conference on Industrial Engineering, Applications and Manufacturing, ICIEAM 2016 - Proceedings. 2016; 7910942.

[8] Zubkov EV, Khaziev ML. Method for Controlling Tracking Actuator. Lecture Notes in Electrical Engineering. 2020;641: 26-34.
[9] Zubkov EV, Khairullin AK. Neural-network simulation of diesel operation under a nonsteady load. Russian Engineering Research. 2016;36(4):262-265.

[10]Khaziev EL, Galiullin LA. Automation of ICE production planning. Journal of Advanced Research in Dynamical and Control Systems. 2019;11(8):17711774.

\section{BIOGRAPHIES OF AUTHORS}

Emil Lutcerovich Khaziev - Associate Professor, Naberezhnye Chelny Institute (branch) KFU/Higher Engineering School/Department of Information Technology and Energy Systems/Department of Information Systems, NI. Academic degrees: Candidate (technical sciences), specialty 05.13.06 - Automation and control of technological processes and production (by industry). Knowledge of languages: English (Independent Speaker).

Lenar Ajratovich Galiullin - Associate Professor, Naberezhnye Chelny Institute (branch) KFU/Higher Engineering School/Department of Information Technology and Energy Systems/Department of Information Systems, NI. Academic degrees: Candidate (technical sciences), specialty 05.13.06 - Automation and control of technological processes and production (by industry), the title of the dissertation "Automation of the technological process of diesel testing based on the fuzzy neural network method". 